\title{
Sex differences in extinction of food-rewarded approach responses*
}

\author{
WILLIAM W. BEATTY and DENNIS A. O'BRIANT \\ liorth Dakota State University, Fargo, N. Dak. 58102
}

Female rats exhibited slower extinction of a food-rewarded running response than did males, but there was no sex difference in extinction of a barpress response that was rewarded by food. It is suggested that sex differences in exploratory activity underlie the differences in extinction.

Female rats acquire active avoidance responses more rapidly than do males (e.g., Beatty \& Beatty, 1970; Denti \& Epstein, 1972); they also are more resistant to the extinction of active avoidance responses (e.g., Beatty, Beatty, \& Bowman, 1971). The present experiments examined the possibility of sex differences in the resistance to extinction of food-rewarded instrumental responses.

\section{EXPERIMENT I Method}

\section{Subjects}

Thirty-four 90-150-day-old Holtzman rats, 17 of each sex, were the Ss. They were caged singly, with free access to water, in an air-conditioned animal room that was lighted from 9 a.m. -9 p.m.

\section{Apparatus}

l.our Gerbrands operant conditioning chambers, each equipped with a cue light, a rat lever, and a pellet feeder, were housed in modified Coleman picnic coolers to provide sound attenuation. An exhaust fan circulated air in the chamber and masked extraneous stimuli. Conventional relay circuitry controlled reinforcement and recorded performance.

\section{Procedure}

Each rat was reduced to $85 \%$ of its free-feeding weight by food deprivation, and maintained at that level for the duration of the experiment. The rats were first shaped to barpress for Noyes pellets in one to two sessions. Next, they received four sessions during which each response was rewarded with a single $45-\mathrm{mg}$ Noyes pellet. Each session lasted until the rat earned 50 reinforcements; typically this required 5-10 min, and there was no sex difference on this measure. Following acquisition, each rat received three extinction sessions, each 15 min long. During extinction, the feeder was disconnected and barpresses were merely recorded.

\section{Results}

As seen in Table 1, females made slightly more responses during extinction than did males, but the effect did not approach an acceptable level of significance $(F=1.55, \mathrm{df}=1 / 32, \mathrm{p}>.10)$. The Sex by Sessions interaction also failed to reach significance $(\mathrm{F}=2.10, \mathrm{df}=2 / 64, \mathrm{p}>.10)$.

*Partially supported by funds from the North Dakota Institute for Regional Studies.
Table 1

\begin{tabular}{|c|c|c|c|c|}
\hline Mean $( \pm$ SD) & Responses & Per Session & During & Extinction \\
\hline & Session 1 & Session & n 2 & Session 3 \\
\hline $\begin{array}{l}\text { Males } \\
\text { Females }\end{array}$ & $\begin{array}{r}87.5 \pm 39.6 \\
109.9 \pm 43.0\end{array}$ & $\begin{array}{l}30.2 \pm 2 \\
34.6 \pm 2\end{array}$ & $\begin{array}{l}25.4 \\
22.4\end{array}$ & $\begin{array}{l}17.5 \pm 18.3 \\
21.2 \pm 12.0\end{array}$ \\
\hline
\end{tabular}

\section{EXPERIMENT II}

This experiment examined sex differences in the extinction of food-rewarded responding, where the approach response was a running response.

\section{Method}

Twenty-two rats, 11 of each sex, were used. All of the animals had been tested previously in Experiment 1 . The present experiment began approximately 5 weeks after the end of Experiment I. During this interval, the rats were caged singly and had free access to food and water. Ad lib body weights were reestablished, and the animals again reduced to $85 \%$ of their free weights by food deprivation; they were maintained at this level for the duration of the experiment.

The apparatus was a straight alley that has been described elsewhere (Beatty, Gregoire, \& Parmiter, 1973). In this experiment, both the shock and the response bar were disconnected.

The rats were given one session of approximately $15 \mathrm{~min}$ to explore the apparatus; they also were trained to eat from the foodcup at this time. Next, the rats were given 10 acquisition sessions of 10 trials each, presented with an intertrial interval of 10-15 sec. Each trial began when the guillotine door was raised, which automatically started a timer and ended when $E$ judged that the rat had touched the foodcup. Three 45-mg Noyes pellets served as the reward. Then the animals received four extinction sessions, each 10 trials long. These tests were exactly like acquisition trials, except that food was not given.

\section{Results}

Figure 1 illustrates the results of both acquisition and extinction tests. During the initial acquisition sessions,

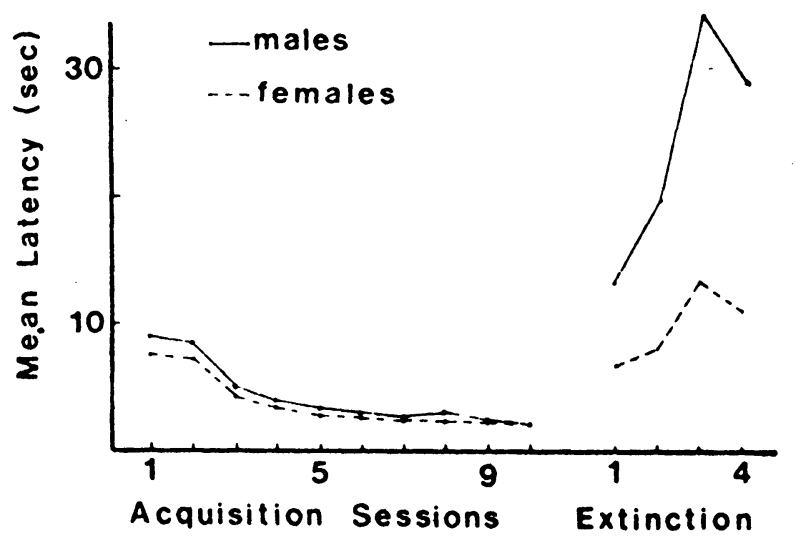

Fig. 1. Average latency from the startbox to the foodcup during acquisition and extinction of a runway response for food. Each data point represents the group mean of individual median latencies for a given session. 
females ran slightly faster than males, but the effect was not significant $(p>.20)$. By the end of acquisition, males and females exhibited nearly identical approach latencies. As shown in the right panel of Fig. 1, females ran faster than males during extinction $(F=7.71$, $\mathrm{df}=1 / 20, \mathrm{p}<.025)$, particularly during the last two extinction sessions.

\section{DISCUSSION}

Female rats displayed increased resistance to the extinction of a running response for food but not of a barpress response for food. The failure to observe a sex difference in the extinction of a food-rewarded barpress response appears to be fairly general. In other experiments, we have failed to observe a sex difference when reward was available on an FR 10 schedule or when the rats were given $10 \mathrm{CRF}$ sessions prior to beginning extinction.

Thus, female rats appear more resistant to the extinction of running responses, whether acquired under hunger or shock motivation (Beatty et al, 1971). These sex differences in extinction performance may, in turn, reflect sex differences in general activity or exploration (Denti, Epstein, 1972), since it is well established that females exhibit greater locomotor activity in a number of test situations.

\section{REFERENCES}

Beatty, W. W., \& Beatty, P. A. Hormonal determinants of sex differences in avoidance behavior and reactivity to electric shock in the rat. Journal of Comparative \& Physiological Psychology, 1970, 73, 446-455.

Beatty, W. w., \& Beatty, P. A., \& Bowman, R. E. A sex difference in the extinction of avoidance behavior in the rat. Psychonomic Science, 1971, 23, 213-214.

Beatty, W. W.. Gregoire, K. C.. Parmiter, L. L. Sex differences in retention of passive avoidance behavior in rats. Bulletin of the Psychonomic Society, 1973, 2, 99-100.

Denti, A., \& Epstein, A. Sex differences in the acquisition of two kinds of avoidance behavior in rats. Physiology \& Behavior, $1972,8,611-615$.

(Received for publication June 4, 1973.) 